\title{
Comparative Evaluation for Potential Differentiation of Endothelial Progenitor Cells and Mesenchymal Stem Cells into Endothelial-Like Cells
}

\author{
Dina Sabry ${ }^{1}$, Olfat $\mathrm{Noh}^{2}$, Mai Samir ${ }^{1}$ \\ ${ }^{1}$ Medical Biochemistry and Molecular Biology, Faculty of Medicine, Cairo University, Cairo, Egypt \\ ${ }^{2}$ Obstetrics and Gynecology Department, Faculty of Medicine, Cairo University, Cairo, Egypt
}

\begin{abstract}
Understanding the mechanisms of vascular remodeling could lead to more effective treatments for ischemic conditions. We aimed to compare between the abilities of both human Wharton jelly derived mesenchymal stem cells (hMSCs) and human cord blood endothelial progenitor cells (hEPCs) and $\mathrm{CD} 34^{+}$to induce angiogenesis in vitro. hMSCs, hEPCs, and $\mathrm{CD} 34^{+}$were isolated from human umbilical cord blood using microbead (MiniMacs). The cells characterization was assessed by flow cytometry following culture and real-time PCR for vascular endothelial growth factor receptor 2 (VEGFR2) and von Willebrand factor (vWF) to prove stem cells differentiation. The study revealed successful isolation of hEPCs, $\mathrm{CD} 34^{+}$, and hMSCs. The hMSCs were identified by gaining $\mathrm{CD} 29^{+}$and $\mathrm{CD} 44^{+}$using FACS analysis. The hEPCs were identified by having $\mathrm{CD} 133^{+}, \mathrm{CD} 34^{+}$, and KDR. The potential ability of hEPCs and $\mathrm{CD} 34^{+}$to differentiate into endothelial-like cells was more than hMSCs. This finding was assessed morphologically in culture and by higher significant VEGFR2 and vWF genes expression $(p<0.05)$ in differentiated hEPCs and CD34 ${ }^{+}$compared to differentiated hMSCs. hEPCs and $\mathrm{CD} 34^{+}$differentiation into endothelial-like cells were much better than that of hMSCs.
\end{abstract}

Keywords: Human endothelial progenitor cells, Human mesenchymal stem cells, CD34 ${ }^{+}$, Endothelial cell differentiation

\section{Introduction}

Angiogenesis is a key factor in the regeneration process in ischemic tissue. Proangiogenic therapies in stroke could increase blood flow, decrease infarct size, and support the restoration and recovery of neurovascular networks after ischemia. Many growth factors, such as VEGF and hypo-

\footnotetext{
Accepted for publication January 23, 2016, Published online May 30, 2016 Correspondence to Dina Sabry

Department of Medical Biochemistry and Molecular Biology, Faculty of Medicine, Cairo University, Cairo 11561, Egypt

Tel: +2-02-23632297, Fax: +2-02-23632297

E-mail: dinasabry@kasralainy.edu.eg

(c) This is an open-access article distributed under the terms of the Creative Commons Attribution Non-Commercial License (http://creativecommons.org/ licenses/by-nc/4.0/), which permits unrestricted non-commercial use, distribution, and reproduction in any medium, provided the original work is properly cited.
}

xia-inducible factor- $1 \alpha$, are described as factors inducing angiogenesis and endothelial cell proliferation (1).

Several types of stem cells have been used for therapeutic neovascularization, including the mesenchymal stem cells (MSCs), which have attracted a great attention. These cells mediate their therapeutic effects by homing to and integrating into injured tissues, differentiating into endothelial cells, and/or producing paracrine growth factors (2).

Endothelial progenitor cells (EPCs) are thought to play an important role in neovascularization and during the regenerative processes after a vascular injury as well as in the maintenance of endothelial integrity and counteracting the progression of cardiovascular disease (3). Activation and mobilization of EPCs from the bone marrow are induced via the production and release of EPC activating factors, such as hypoxia-inducible factor-1, estrogen, VEGF, 
or erythropoietin, in response to peripheral tissue hypoxia, such as after acute ischemic stroke or trauma (4).

Several mediators induce angiogenesis, including members of the fibroblast growth factor (FGF) family (5), vascular endothelial growth factor (VEGF) (6), epidermal growth factor (EGF) (7), tumor necrosis factor (TNF- $\alpha$ ) (8), and certain members of the CXC chemokine family (9). SDF-1 $\alpha$ is a highly efficient chemotactic factor for $\mathrm{T}$ cells, monocytes, pre-B-cells, dendritic cells, and hematopoietic progenitor cells. SDF-1 $\alpha$ mediates its cellular effects such as $\mathrm{Ca}^{2+}$ mobilization, cell migration, and angiogenesis mainly by binding to its chemokine receptor (CXCR-4). Although SDF-1 $\alpha$ binds to other receptors such as CXCR7, ligand activation of CXCR7 does not cause $\mathrm{Ca}^{2+}$ mobilization or cell migration. SDF-1 $\alpha$ is the predominant chemokine that mobilizes HSCs and EPCs (10). In the present study, we aimed to compare between potential efficacies of MSCs derived from human Wharton jelly and EPCs and $\mathrm{CD}_{3} 4^{+}$derived from human umbilical cord blood for angiogenesis development in vitro.

\section{Materials and Methods}

Twenty samples of human umbilical cord blood and Wharton jelly were collected for isolation and culture of EPCs and MSCs. The inclusion criteria were cord blood of full-term labor, age of 25 40 years, and not complaining of chronic disease like ischemia or vascular occlusion disease. The exclusion criteria were cord blood of abortion or fetal death, patients having chronic disease as diabetes mellitus or hypertension, and ischemic patients.

\section{Isolation, Expansion, and Characterization of Different Types of Stem Cells}

Human umbilical cord (hUC) specimens were obtained using protocols approved by the Ethical Committee of Faculty of Medicine, Cairo University.

\section{Mesenchymal Stem Cells}

After obtaining each patient's own informed consent, 20 fresh UC samples of women with healthy pregnancies were retrieved at the end of gestation during caesarean deliveries from Department of Obstetrics and Gynecology. hUC Wharton jelly was harvested from term deliveries at the time of birth with the mother's consent. hUCMSC was isolated by $3 \mathrm{mg}$ collagenase II enzyme (IgG, C. histolyticum, US Biological, Life Science) digestion and maintained in $2 \%$ fetal bovine serum and $1 \mathrm{x}$ Pen/Strep (Invitrogen, CA). Cells were incubated at $37^{\circ} \mathrm{C}$ in an incubator with $5 \% \mathrm{CO} 2$ at saturating humidity till they reach $70 \% \sim 80 \%$ confluency; cultures were washed twice with phosphate buffer saline (PBS) and cells were trypsinized with $0.25 \%$ trypsin for 5 minutes at $37^{\circ} \mathrm{C}$. After centrifugation, cell pellets were resuspended with serum-supplemented medium and incubated in $50 \mathrm{~cm}^{2}$ culture flask (GIBCO/BRL). The resulting cultures were referred to as first-passage cultures (11).

We further characterized and quantified expressions of several Wharton Jelly mesenchymal stem cell markers (at the end of the 4th passage). Cells were trypsinized and adjusted to $1 \times 10^{6}$ cells $/ \mathrm{ml}$. Then $1 \times 10^{5}$ cells were incubated with $10 \mu \mathrm{l}$ of monoclonal antibodies: CD29 PE and $\mathrm{CD} 44 \mathrm{PE}$, at $4^{\circ} \mathrm{C}$ in the dark; the same species isotypes served as a negative control. After $20 \mathrm{~min}$ incubation, $2 \mathrm{ml}$ of PBS containing 2\% FCS solution was added to each tube of monoclonal treated cells. The mixtures were then centrifuged for $5 \mathrm{~min}$ at $2500 \mathrm{rpm}$ followed by discarding the supernatant and resuspending cells in $500 \mu 1$ PBS containing 2\% FCS. Cell analysis was performed using CYTOMICS FC 500 Flow Cytometer (Beckman Coulter, FL, USA) and using CXP software version 2.2.

\section{Endothelial Progenitor Stem Cells}

The technique used for collecting UCB from the umbilical vein is the in utero technique. With the in utero technique, the blood is collected in the delivery room while the placenta is still inside the uterus. The in utero technique is more preferred than any other technique, because it is faster and simpler. Only one person is necessary and there is a lower risk of blood contamination, as it is not necessary to move the placenta before the blood is collected. Thirty seconds after delivery, the umbilical cord is clamped and cleaned with betadine solution. The UCB is collected from the umbilical vein with a 12.5-gauge needle connected to a sterile $50 \mathrm{ml}$ Falcon tissue culture tube, containing $10 \mathrm{ml}$ of phosphate-citrate-dextrose anticoagulant. The umbilical cord is "milked" and the uterus is gently massaged during the last period of the collection in order to increase the blood flow (12). The hUCB mononuclear cell fraction was isolated from the buffy coats through density gradient centrifugation with Ficoll-Paque (Gibco-Invitrogen, Grand Island, NY). Anticoagulated blood sample was carefully layered on $20 \mathrm{ml}$ Ficoll and then centrifuged for 35 minutes at $400 \mathrm{xg}$. The upper layer was aspirated leaving the hUCB mononuclear cell layer undisturbed at the interphase. The interphase layer, the hUCB mononuclear cell layer, was carefully aspirated and washed twice in PBS containing $2 \mathrm{mM}$ EDTA and centrifuged for 10 minutes at $200 \mathrm{xg}$ at $20^{\circ} \mathrm{C}$. The cell pellet was re- 
suspended in a final volume of $300 \mu 1$ of buffer. $12 \times 10^{6}$ MNCs (isolated from twenty hUCB samples) were layered onto fibronectin coated 96-well plates and cultured in M199 medium supplemented with $20 \%$ fetal calf serum (FCS), $0.1 \%$ human vascular endothelial growth factor-1 (VEGF1), and $0.1 \%$ insulin-like growth factor (IGF-1) at $37^{\circ} \mathrm{C}$ for 48 hours, after which the supernatant was removed (13). The purity of the CD34 $4^{+}$of MNCs was evaluated by flow cytometry. Mononuclear cells were incubated with Dil-Ac-LDL $(6 \mu \mathrm{g} / \mathrm{ml})$ for $1 \mathrm{~h}$ at $37^{\circ} \mathrm{C}$ in the dark. Thereafter, the cells were washed twice with PBS at $37^{\circ} \mathrm{C}$ and incubated with FITC Conjugated Ulex Lectin $(10 \mu \mathrm{g} / \mathrm{ml})$ for one hour at $37^{\circ} \mathrm{C}$ in the dark. After two final washing steps with $\mathrm{PBS}$ at $37^{\circ} \mathrm{C}$, the cells were fixed and subsequently analyzed for uptake of Dil-Ac-LDL and binding of FITC-Ulex lectin using a Leica inverted fluorescence microscope.

\section{Magnetic Cell Sorting of CD34 ${ }^{+}$Cells}

UC was diluted to $1: 4$ with phosphate buffered saline (PBS) containing $2 \mathrm{mM}$ EDTA (Gibco-Invitrogen, Grand Island, NY). MNCs were separated by centrifugation over a Ficoll-Paque (Gibco-Invitrogen, Grand Island, NY) density gradient at $400 \mathrm{xg} \mathrm{rpm}$ for 35 minutes at $20^{\circ} \mathrm{C}$. The MNC fraction was collected and washed first in PBS and then with MACS (magnetic cell sorting) buffer (PBS supplemented with $0.5 \%$ bovine serum albumin and $2 \mathrm{mM}$ EDTA, $\mathrm{pH}$ 7.2). $\mathrm{CD} 34^{+}$cells were isolated from MNCs, using the $\mathrm{CD}_{3} 4^{+}$positive cell selection kit (MiniMacs; Miltenyi Biotec, Bergisch Gladbach, Germany). Isolation of $\mathrm{CD} 34^{+}$cells was confirmed by flow cytometry.

\section{Differentiation of Isolated Stem Cells to Endothelial-Like Cells}

After the seven-day expansion period, the identified cells were collected and counted. Thereafter the conditioned medium was removed and the cells were cultured $\left(3 \times 10^{5} \sim 1 \times 10^{6} / 1.5 \mathrm{ml} / 9.6 \mathrm{~cm}^{2}\right)$ in endothelial cell growth medium-2 (EGM-2) containing FBS (2\%), hydrocortisone,
hFGF, VEGF, R3-IGF-1, ascorbic acid, hEGF, gentamycin, amphotericin-B, and heparin (Lonza, Basel, Switzerland). After three days of culture, the cells were collected and transferred to plates coated with fibronectin $(10 \mathrm{mg} / \mathrm{ml})$ (Sigma-Aldrich, St. Louis, USA) at a density of $1 \times 10^{6}$ cells $/ 1.5 \mathrm{ml} / 9.6 \mathrm{~cm}^{2}$ and cultured for an additional three days in fresh EGM-2 medium. Real-time PCR was done for VEGFR2 and von Willebrand genes to ensure the presence of different types of stem cells.

\section{Immunophenotyping Characterization of Differentiated Stem Cells}

We further characterized and quantified expression of several endothelial cell markers. $1 \times 10^{5}$ cells were incubated with $10 \mu 1$ of monoclonal antibodies: CD31 FITC and VE-cadherin PE (Beckman coulter, USA) at $4^{\circ} \mathrm{C}$ in the dark; the same species isotypes served as a negative control. After 20 minutes incubation, $2 \mathrm{ml}$ of PBS containing $2 \%$ FCS solution was added to each tube of monoclonal treated cells. The mixtures were then centrifuged for 5 minutes at $2500 \mathrm{rpm}$ followed by discarding the supernatant and resuspending cells in $500 \mu 1 \mathrm{PBS}$ containing $2 \%$ FCS. Cell analysis was performed using CYTOMICS FC 500 Flow Cytometer (Beckman coulter, FL, USA) and using CXP software version 2.2.

\section{Quantitative Genes Expression by Real-Time PCR}

Real-time qPCR amplification and analysis were performed using an Applied Biosystems software version 3.1 (StepOne ${ }^{\mathrm{TM}}$, USA). The $\mathrm{qPCR}$ assay and the primer sets were optimized at the annealing temperature. All cDNA, including previously prepared samples (for VEGFR2 and von Willebrand), internal control (for GAPDH gene expression as housekeeping gene), and non-template control (water to confirm the absence of DNA contamination in the reaction mixture), was in duplicate. Primers sequences of all assessed genes were illustrated in Table 1.

Table 1. The primers sequences of genes

\begin{tabular}{llc}
\hline Gene symbol & \multicolumn{1}{c}{ Primer sequence 5'-3' } & GBAN $^{\mathrm{a}}$ \\
\hline VEGFR2 & F: GATGTGGTTCTGAGTCCGTCT & NT022853.15 \\
& R: CATGGCTCTGCTTCTCCTTTG & HF571250.1 \\
von Willebrand & F: TAAGTCTGAAGTAGAGGTGG & NT009759.16 \\
& R: AGAGCAGCAGGAGCACTGGT \\
\hline
\end{tabular}

\footnotetext{
${ }^{\mathrm{a}} \mathrm{GBAN}$ : Gene Bank accession number.
} 


\section{Statistical analysis}

Statistical analyses were done using Statistical Package for Social Studies (SPSS) software, version 11, for Windows. The clinical scores were shown as the mean \pm standard deviation. Data were analyzed statistically by Friedman's test and the Wilcoxon signed-rank test. p values of less than 0.05 were accepted as significant.

\section{Results}

Wharton jelly derived MSCs and umbilical cord derived EPCs were isolated, propagated, characterized by FACS analysis, and differentiated into endothelial-like cells. EPCs were identified in culture on fibronectin plates by formation of spindle shape and cobblestone-like cells (Fig. 1A). MSCs were identified by their morphological fibroblast spindle shape and adhesiveness as shown in Fig. 1B. CD $34^{+}$was selectively isolated from human umbilical cord blood using microbeads and was cultured (Fig. 1C). The cells were subjected to fluorescence-activated cell sorting using FACS and Cell Quest software (Becton Dickinson, San Jose, CA) for identification and characterization of isolated stem cells. EPCs were positive for CD133 and CD34 and highly positive for VEGFR2 (KDR) as shown
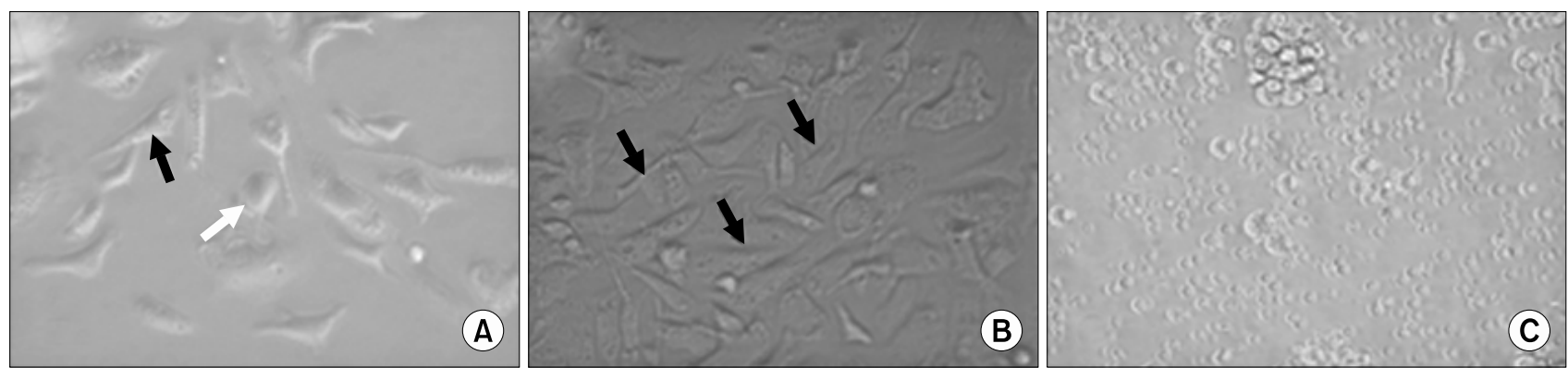

Fig. 1. (A) Undifferentiated EPCs cultured on fibronectin plate. After 14-day culture, a spindle-shaped (black arrow) and cobblestone-like (white arrow) morphology is typical for EPCs. (B) Spindle-shaped (black arrows) MSCs after two weeks in culture with 80 90\% confluence. (C) $\mathrm{CD}_{4} 4^{+}$cells in culture at 0 day after isolation from hUC using microbeads. CD $34^{+}$cells were rounded nonadherent cells.

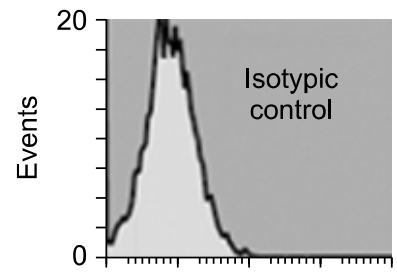

FL2 Log

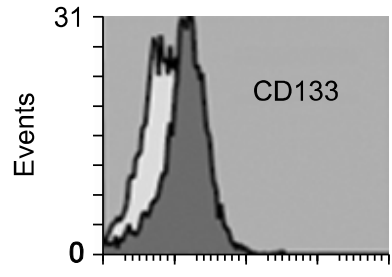

FL2 Log

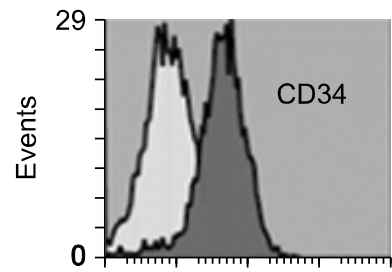

FL2 Log

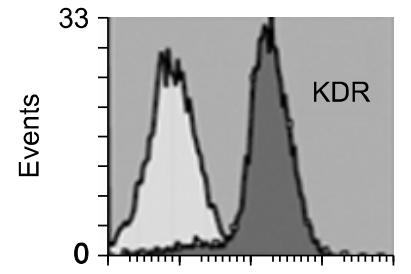

FL2 Log

Fig. 2. FACS characterization of EPCs. Cells were uniformly positive for specific cell surface markers CD133, CD34, and KDR.
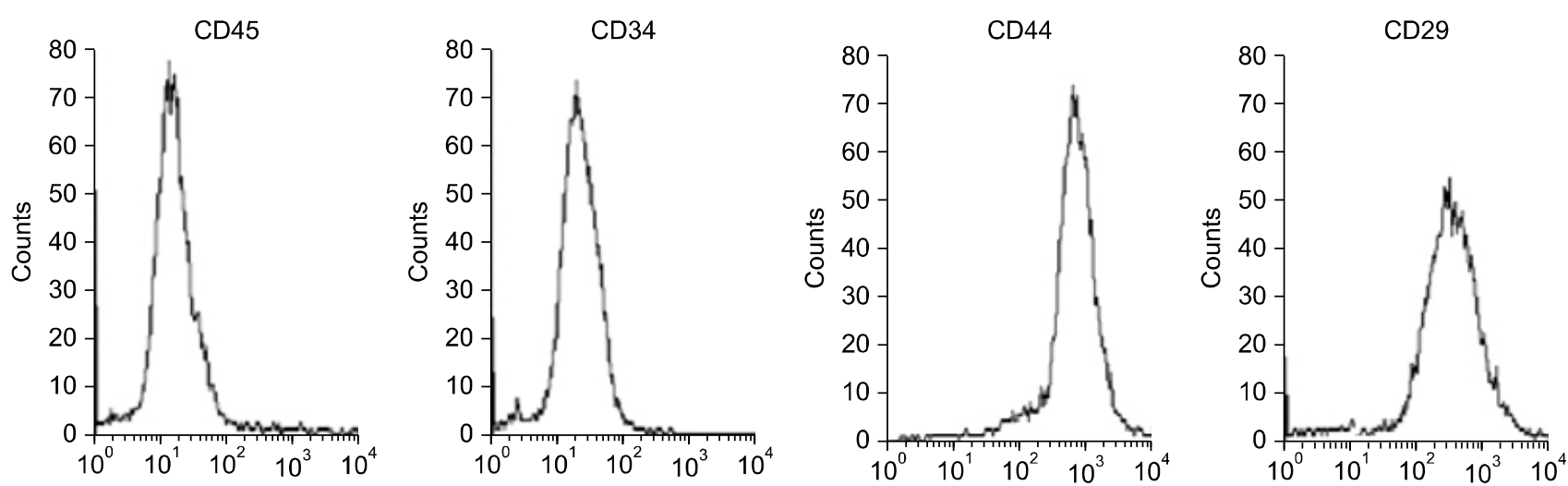

Fig. 3. FACS characterization of MSCs. Cells were uniformly negative for CD34 and CD45 and positive for CD44 and CD29. 

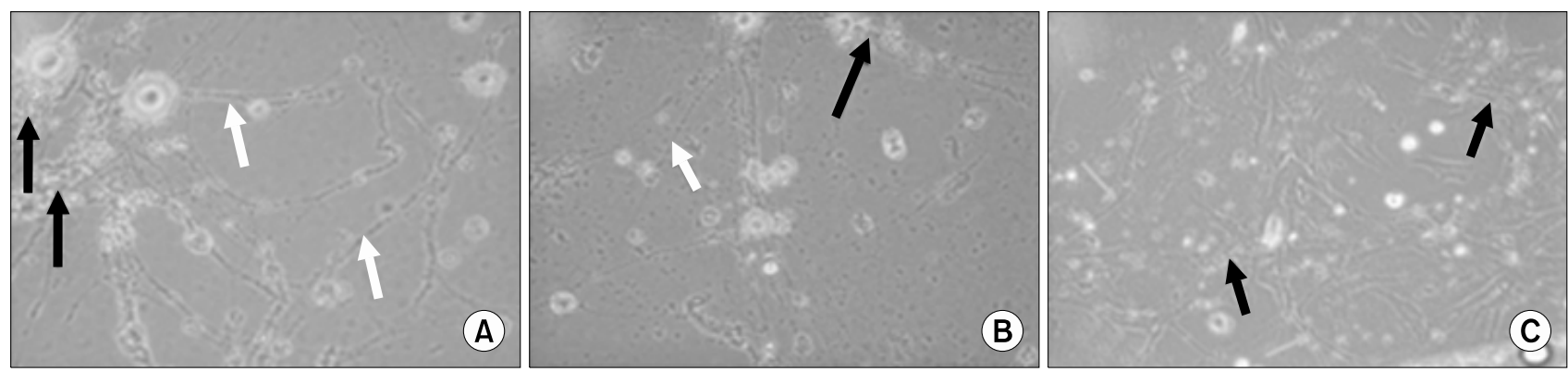

Fig. 4. (A) The cluster formation (black arrows) and tubular network formation (white arrows) were highly identified in EPCs differentiated into endothelial-like cells. (B) The cluster formation (black arrows) and tubular network formation (white arrows) were identified in MSCs differentiated into endothelial-like cells. (C) CD34 ${ }^{+}$differentiated in culture after 14 days into endothelial-like cells. CD34 ${ }^{+}$differentiated as clusters (black arrows) and tubular network formation (white arrows).

Table 2. Quantitative RT-PCR of VEGFR2 and von Willebrand genes expression

\begin{tabular}{lccccc}
\hline & Undifferentiated EPCs & Undifferentiated MSCs & Differentiated EPCs & Differentiated MSCs & CD34 $^{+}$ \\
\hline VEGFR2 & $0.280 \pm 0.156$ & $0.238 \pm 0.122$ & $0.607 \pm 0.201^{\mathrm{a}, \mathrm{b}}$ & $0.205 \pm 0.061^{\mathrm{c}}$ & $0.461 \pm 0.105^{\mathrm{d}}$ \\
VWF & $0.640 \pm 0.118$ & $0.491 \pm 0.160$ & $1.318 \pm 0.699^{\mathrm{b}}$ & $0.627 \pm 0.323$ & $1.274 \pm 0.387^{\mathrm{b}}$ \\
\hline
\end{tabular}

Values are represented as mean $\pm \mathrm{SD}$.

aStatistically significant compared to corresponding value in undifferentiated EPCs group $(p<0.05)$.

${ }^{b}$ Statistically significant compared to corresponding value in undifferentiated MSCs group $(p<0.05)$.

'Statistically significant compared to corresponding value in differentiated EPCs group $(p<0.05)$.

${ }^{\mathrm{d}}$ Statistically significant compared to corresponding value in differentiated MSCs group $(p<0.05)$.

in Fig. 2.

MSCs were positive for CD44 and CD29 and negative for CD34 and CD45 (Fig. 3). Differentiated EPCs have their ability for angiogenesis by formation of cluster of cells with tubular network branches (Fig. 4A). Differentiated MSCs have their ability for angiogenesis, but lesser than that of EPCs by less formation of cluster of cells with tubular network branches (Fig. 4B). CD34 ${ }^{+}$ differentiated into endothelial-like cells for 14 days (Fig. $4 \mathrm{C})$.

On studying the quantitative RT-PCR of VEGFR2 and von Willebrand genes expression in vitro (Table 2), our results showed that the quantitative RT-PCR of VEGFR2 in differentiated EPCs showed a statistically significant expression compared to the corresponding value in undifferentiated EPCs group and in undifferentiated MSCs group. We also noticed that the quantitative RT-PCR of VEGFR2 in $\mathrm{CD} 34^{+}$showed a statistically significant expression compared to the corresponding value in differentiated MSCs group (Fig. 5). As regards the quantitative RT-PCR of von Willebrand genes expression in vitro, its values in differentiated EPCs group and $\mathrm{CD} 34^{+}$group showed a statistically significant expression compared to the corresponding value in undifferentiated MSCs group (Fig. 6). We confirmed the differentiation of EPCs, MSCs,

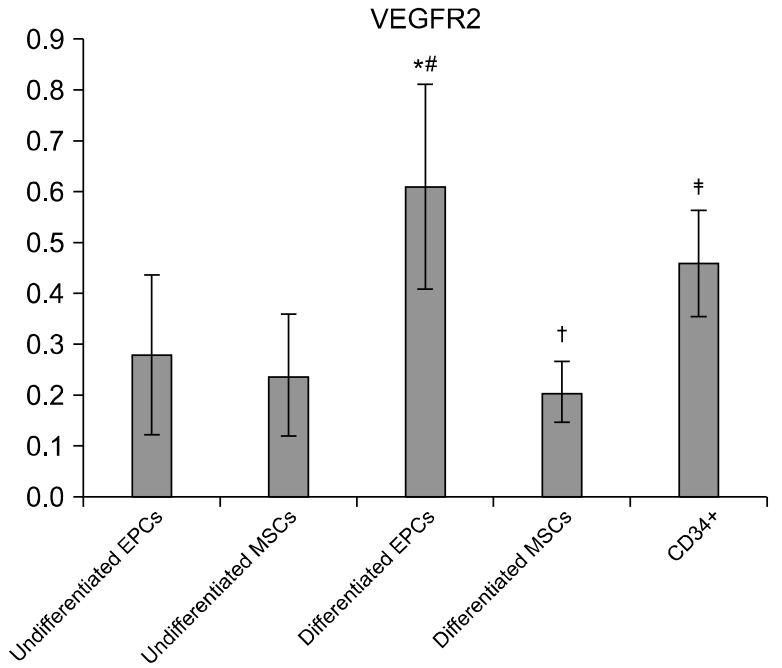

Fig. 5. Quantitative RT-PCR of VEGFR2 gene expression in vitro in all studied groups. ${ }^{\dagger}$ Statistically significant compared to corresponding value in differentiated EPCs group $(p<0.05)$. ${ }^{\ddagger}$ Statistically significant compared to corresponding value in differentiated MSCs group $(\mathrm{p}<0.05)$.

and $\mathrm{CD} 34^{+}$by FACS analysis for endothelial surface markers such as $\mathrm{CD} 31^{+}$and VE-cadherin (Figs. 7 and 8, resp.). $\mathrm{CD} 31^{+}$and VE-cadherin are highly expressed on differentiated EPCs and $\mathrm{CD} 34^{+}$compared to differ- 
entiated MSCs.

\section{Discussion}

The hUC is normally discarded after birth. Therefore, UC collection does not require any invasive procedure and

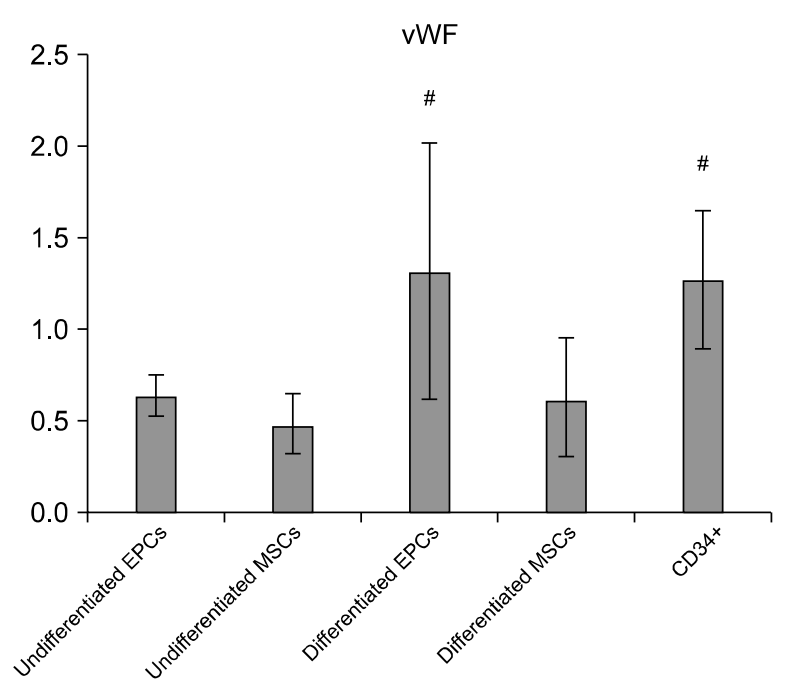

Fig. 6. Quantitative RT-PCR of von Willebrand gene expression in vitro in all studied groups. does not imply major ethical concerns. Wharton's jelly derived MSCs have shown multilineage capability along with immunoregulatory properties. It has been shown that a single injection of major histocompatibility complex (MHC) mismatched unactivated hUCMSCs did not induce a detectable immune response; therefore, they can be tolerated in allogeneic transplantation. So there are many advantages of hUCMSCs including widespread availability, absence of donor risk, low risk of transmissible infectious diseases, decreased graft-versus-host disease, and increased precursors of immune effector cells (14). Several types of stem cells have been used for therapeutic neovascularization, including the mesenchymal stem cells, which have attracted a great attention. These cells mediate their therapeutic effects by homing to and integrating into injured tissues, differentiating into endothelial cells, and/or producing paracrine growth factors (2).

EPCs are thought to play an important role in neovascularization and during the regenerative processes after a vascular injury as well as in the maintenance of endothelial integrity and counteracting the progression of cardiovascular disease (3). This research study aims to address the main aspects of EPCs differentiation and certain characteristics of their main function, especially in angiogenesis, as well as the potential future clinical applications.
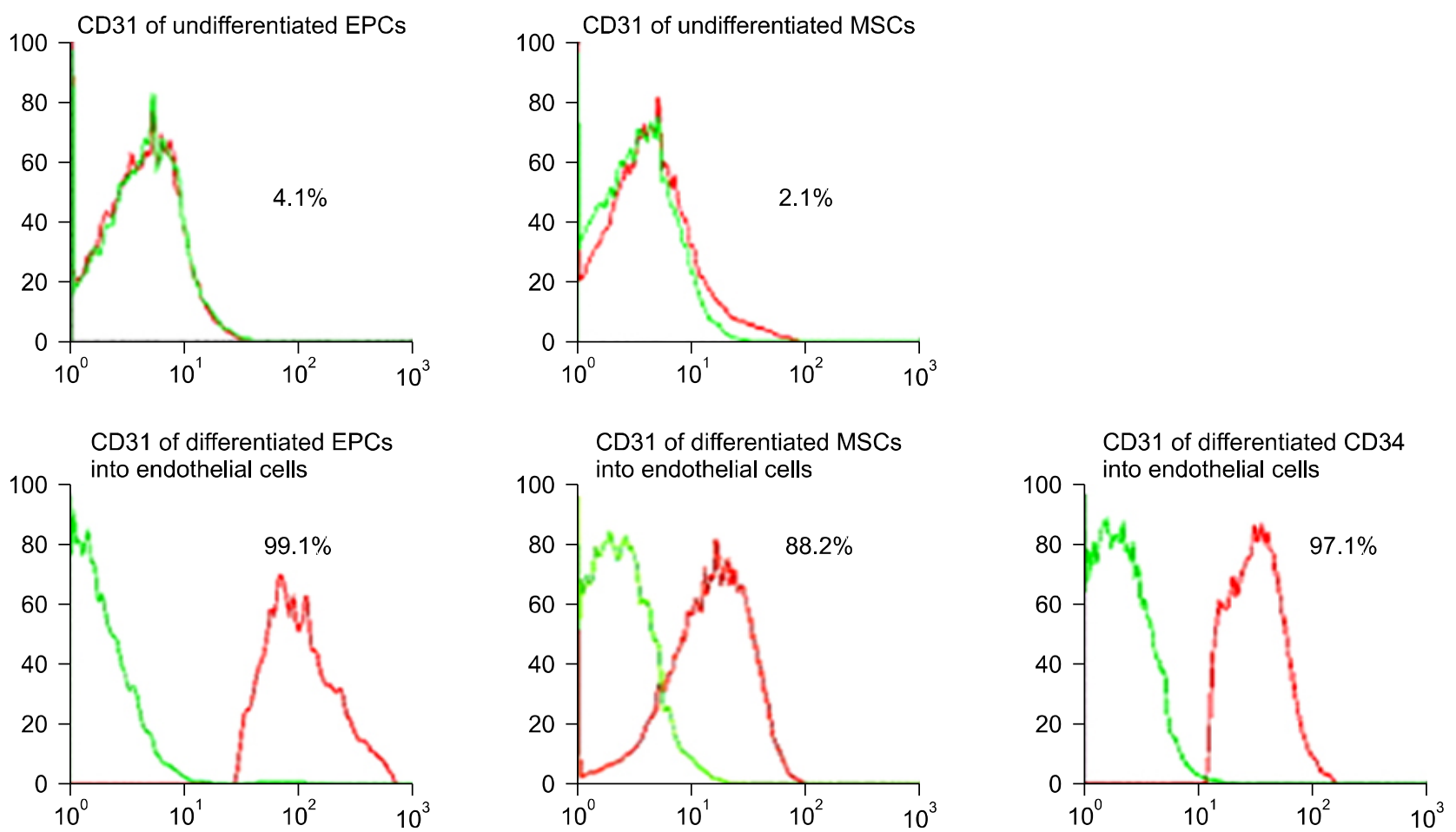

Fig. 7. FACS analysis of CD31 in all studied groups with high expression in differentiated EPCs and CD34 ${ }^{+}$compared to differentiated MSCs. 

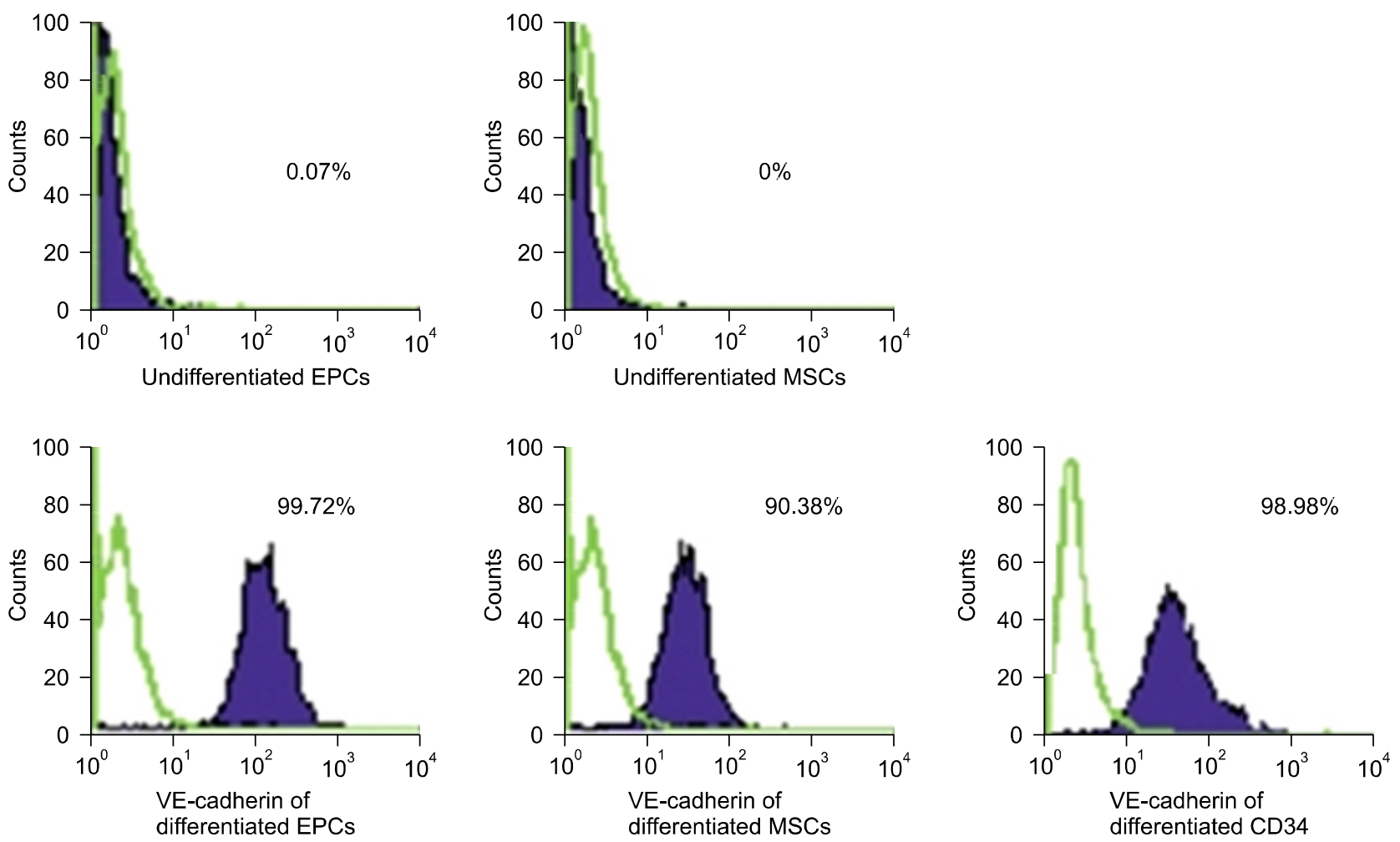

Fig. 8. FACS analysis of VE-cadherin in all studied groups with high expression in differentiated EPCs and CD34 ${ }^{+}$compared to differentiated MSCs.

Activation and mobilization of EPCs from the bone marrow are induced via the production and release of EPC activating factors, such as hypoxia-inducible factor-1, estrogen, VEGF, or erythropoietin, in response to peripheral tissue hypoxia such as after acute ischemic stroke or trauma (4).

Vascularization plays an important role in tissue engineering applications. It is known that implantation of differentiated endothelial cells or endothelial progenitor cells (EPCs) from cord blood (cbEPCs) gives rise to the formation of a complex functional neovasculature, whereas EPCs isolated from peripheral blood (pbEPCs) have a limited capability to form blood vessels upon implantation (15).

New researchers achieved possibility of isolation and characterization of human umbilical cord blood EPCs and examination of potency of EPCs to form new blood vessels and to differentiate into cardiomyocytes in canines with acute myocardial infarction (AMI). Human VEGFR2 and eNOS from the cultured EPCs were assessed by qPCR. Human EPCs were transplanted intramyocardially in canines with AMI. Histopathology showed increased neovascularization and immunostaining showed presence of EPCs newly differentiated into cardiomyocyte-like cells.
These findings suggested that hEPCs can mediate angiogenesis and differentiate into cardiomyocytes in canines with AMI (16).

The above results agreed with our recent work as regards significant increase of VEGFR2 and vWF genes expression in differentiated ex vivo expanded EPCs cultured cells as compared to $\mathrm{CD} 34^{+}$, undifferentiated EPCs, undifferentiated MSCs, and differentiated MSCs. Preselected $\mathrm{CD} 34^{+}$cells do not express CD45; rather they acquire it during differentiation into hematopoietic progenitor cells, except if they are destined to differentiate into endothelial cells.

Differentiation of EPCs or MSCs with VEGF also upregulates the expression of the VEGF receptor KDR, which plays a major role in angiogenesis in vivo and contributes to the formation of capillary-like structures in vitro. However, the significantly higher number of differentiated EPCs compared to differentiated MSCs could be beneficial in the engineering of complex tissues, where vascularization of the tissue is an essential feature for the successful engraftment. Clinical studies will have to prove whether the systemic application of predifferentiated endothelial EPCs or MSCs may have positive effects in patients with small vessel diseases. 
Recent researchers studied in vitro the effects of FGF2 on the differentiation of human bone marrow AC133(+) cells (BM-AC133(+)) into vascular precursors. FGF2, like VEGFA, induced progenitor cell differentiation into cell types with endothelial cell characteristics (17).

Previous results coincided with our present work as regards successfully isolated human cord blood EPCs that were confirmed by FACS as having $\mathrm{CD}_{133^{+}}$and $\mathrm{KDR}$ and also the ability of endothelial basal medium that contains hFGF to differentiate successfully isolated human cord blood EPCs into endothelial like cells.

Zhang et al. in 2015 (18) stated that CD31 expression is increased during differentiation of isolated EPCs from human umbilical vein endothelial cell (HUVEC) and Obi et al. in 2014 (19) confirmed VE-cadherin protein expression as an endothelial marker of differentiation of expanded EPCs. Our study work confirmed the differentiation of EPCs derived from cord blood into endothelial cells by higher expression of CD31 and VE-cadherin compared to isolated and differentiated MSCs and CD34 ${ }^{+}$.

In conclusion, we reported that human EPC as defined by expression of VEGFR2 and CD133 can be obtained from hUCB using CD34 selection. These cells can be differentiated in culture to express markers of mature EC, while keeping progenitor markers. Under the conditions described in this paper, cells with endothelial markers can also be generated from unselected MNC. However, the concomitant expression of monocytic and hematopoietic lineage markers and their lack of progenitor cell associated markers may cast some doubt on their usefulness as true endothelial progenitors.

\section{Potential conflict of interest}

The authors have no conflicting financial interest.

\section{References}

1. Marti HJ, Bernaudin M, Bellail A, Schoch H, Euler M, Petit E, Risau W. Hypoxia-induced vascular endothelial growth factor expression precedes neovascularization after cerebral ischemia. Am J Pathol 2000;156:965-976

2. Li Y, Zhang D, Zhang Y, He G, Zhang F. Augmentation of neovascularization in murine hindlimb ischemia by combined therapy with simvastatin and bone marrow-derived mesenchymal stem cells transplantation. J Biomed Sci 2010;17:75

3. Ho TK, Shiwen X, Abraham D, Tsui J, Baker D. Stromal-cell-derived factor-1 (SDF-1)/CXCL12 as potential target of therapeutic angiogenesis in critical leg ischaemia. Cardiol Res Pract 2012;2012:143209

4. Liman TG, Endres M. New vessels after stroke: pos- tischemic neovascularization and regeneration. Cerebrovasc Dis 2012;33:492-499

5. Aviles RJ, Annex BH, Lederman RJ. Testing clinical therapeutic angiogenesis using basic fibroblast growth factor (FGF-2). Br J Pharmacol 2003;140:637-646

6. Awata T, Inoue K, Kurihara S, Ohkubo T, Watanabe $M$, Inukai $\mathrm{K}$, Inoue I, Katayama S. A common polymorphism in the 5'-untranslated region of the VEGF gene is associated with diabetic retinopathy in type 2 diabetes. Diabetes 2002;51:1635-1639

7. Harris VK, Coticchia CM, Kagan BL, Ahmad S, Wellstein A, Riegel AT. Induction of the angiogenic modulator fibroblast growth factor-binding protein by epidermal growth factor is mediated through both MEK/ERK and p38 signal transduction pathways. J Biol Chem 2000;275:10802-10811

8. Schultz GS, Grant MB. Neovascular growth factors. Eye (Lond) 1991;5:170-180

9. Strasly M, Doronzo G, Cappello P, Valdembri D, Arese M, Mitola S, Moore P, Alessandri G, Giovarelli M, Bussolino F. CCL16 activates an angiogenic program in vascular endothelial cells. Blood 2004;103:40-49

10. Sameermahmood Z, Balasubramanyam M, Saravanan T, Rema M. Curcumin modulates SDF-1alpha/CXCR4- induced migration of human retinal endothelial cells (HRECs). Invest Ophthalmol Vis Sci 2008;49:3305-3311

11. Weiss ML, Medicetty S, Bledsoe AR, Rachakatla RS, Choi M, Merchav S, Luo Y, Rao MS, Velagaleti G, Troyer D. Human umbilical cord matrix stem cells: preliminary characterization and effect of transplantation in a rodent model of Parkinson's disease. Stem Cells 2006;24:781-792

12. Volpe G, Santodirocco M, Di Mauro L, Miscio G, Boscia FM, Muto B, Volpe N. Four phases of checks for exclusion of umbilical cord blood donors. Blood Transfus 2011;9: 286-291

13. Matsuo Y, Imanishi T, Hayashi Y, Tomobuchi Y, Kubo T, Hano T, Akasaka T. The effect of endothelial progenitor cells on the development of collateral formation in patients with coronary artery disease. Intern Med 2008;47:127-134

14. Anzalone R, Corrao S, Lo Iacono M, Loria T, Corsello T, Cappello F, Di Stefano A, Giannuzzi P, Zummo G, Farina F, La Rocca G. Isolation and characterization of CD276+/ HLA-E+ human subendocardial mesenchymal stem cells from chronic heart failure patients: analysis of differentiative potential and immunomodulatory markers expression. Stem Cells Dev 2013;22:1-17

15. Goerke SM, Kiefer LS, Stark GB, Simunovic F, Finkenzeller G. miR-126 modulates angiogenic growth parameters of peripheral blood endothelial progenitor cells. Biol Chem 2015;396:245-252

16. Abd El Aziz MT, Abd El Nabi EA, Abd El Hamid M, Sabry D, Atta HM, Rahed LA, Shamaa A, Mahfouz S, Taha FM, Elrefaay S, Gharib DM, Elsetohy KA. Endothelial progenitor cells regenerate infracted myocardium with neovascularisation development. J Adv Res 2015;6:133-144

17. Fons P, Gueguen-Dorbes G, Herault JP, Geronimi F, Tuyaret J, Frédérique D, Schaeffer P, Volle-Challier C, 
Herbert JM, Bono F. Tumor vasculature is regulated by FGF/FGFR signaling-mediated angiogenesis and bone marrow-derived cell recruitment: this mechanism is inhibited by SSR128129E, the first allosteric antagonist of FGFRs. J Cell Physiol 2015;230:43-51

18. Zhang C, Li Y, Wang J, Li K. [The Supernatant Obtained from Cultured Anip973 Cells Enhances the Biological
Activities of HUVEC]. Zhongguo Fei Ai Za Zhi 2015;18: 668-673

19. Obi S, Masuda H, Akimaru H, Shizuno T, Yamamoto K, Ando J, Asahara T. Dextran induces differentiation of circulating endothelial progenitor cells. Physiol Rep 2014; 2:e0261 